\title{
Análise de processos éticos: tipos penais no exercicio da enfermagem
} Analysis of ethical issues: criminal acts in nursing practice Análisis de procesos éticos: tipos penales en el ejercicio de la enfermería

Fabíola de Campos Braga Mattozinho ${ }^{1}$ id https://orcid.org/0000-0002-3084-6897

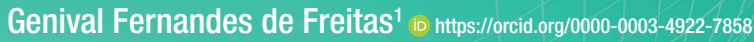

\section{Como citar:}

Mattozinho FC, Freitas GF. Análise de processos éticos: tipos penais no exercício

da enfermagem. Acta Paul Enferm. 2021;34:eAPE00243.

DOI

http://dx.doi.org/10.37689/actaape/2021A000243

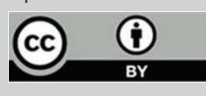

Descritores

Ética em enfermagem; Organizações de normalização profissional; Códigos de ética; Responsabilidade profissional; Prática profissional/

ética

Keywords

Nursing ethics; Organizations of professional normalization; Ethics codes; Professional responsibility; Professional practice/ethics

\section{Descriptores}

Ética en enfermería; Organizaciones de normalización profesional; Códigos de ética; Responsabilidad professional; Práctica profesional/

etica

Submetido 12 de Fevereiro de 2020

Aceito

20 de Agosto de 2020

Autor correspondente Fabíola de Campos Braga Mattozinho

E-mail: fabiolacb@hotmail.com

\section{Resumo}

Objetivo: Identificar tipos penais no exercício da enfermagem e a existência de fatores relacionados a conduta profissional nas ocorrências éticas envolvendo tipos penais a partir da análise de depoimentos contidos nos processos éticos julgados no Conselho Regional de Enfermagem de São Paulo (Coren/SP).

Métodos: Estudo exploratório-descritivo de abordagem quanti-qualitativa, nos processos éticos contendo ilícitos éticos considerados tipos penais. Os dados foram coletados nos processos ético-profissionais de enfermagem julgados pelo Coren/SP em 2012 e 2013.

Resultados: Os tipos penais evidenciados na análise foram: abandono de incapaz; apropriação indébita; importunação sexual; estelionato; exercício ilegal de profissão; exercício ilegal da medicina; falsidade ideológica; extravio, sonegação ou inutilização de livro ou documento; falsificação de documento; falsificação, corrupção, adulteração ou alteração de produto destinado a fins terapêuticos ou medicinais; furto; homicídio; lesão corporal; maus tratos; peculato; tráfico de entorpecentes; uso de documento falso e vilipêndio a cadáver. Dos depoimentos emergiram sete categorias temáticas: Arrependimento Posterior; Percepção do ato ilícito; Fatores relacionados às condições de trabalho; Fatores Psicológicos e/ou sociais; Fatores Financeiros; Inobservância da responsabilidade e Dualidade.

Conclusão: Os resultados do estudo foram de suma importância para identificar as ocorrências envolvendo tipos penais e com isso, a necessidade de se aprofundar a discussão sobre os problemas éticos na prática cotidiana do trabalho em enfermagem. Nessa perspectiva, o estudo denota a necessidade de se investir em melhores condições de trabalho e na formação qualificada dos profissionais de enfermagem no seu cotidiano, valorizando-os e incentivando-os à prática ética e humanizada do outro e de si.

\section{Abstract}

Objective: To identify criminal acts in nursing practice and the existence of factors related to professional behavior in ethical issues involving crime, based on the analysis of testimonies contained in ethical lawsuits judged by the Regional Nursing Council of São Paulo (Coren/SP).

Methods: Exploratory descriptive study with a quantitative and qualitative approach, analyzing ethical lawsuits containing ethical illicit acts considered criminal acts. Data were collected in the ethical-professional nursing lawsuits judged by Coren/SP in 2012 and 2013.

Results: The criminal acts evidenced in the analysis were: abandonment of disabled person; embezzlement; sexual abuse; swindling; criminal impersonation; illegal practice of medicine; identity fraud; loss, fraud or destruction of a book or document; forgery of document; counterfeiting, contamination, adulteration or alteration of product intended for therapeutic or medicinal purposes; theft; bodily injury; maltreatment; 
peculation; drug trafficking; use of false document and abuse of corpse. The testimonies gave rise to seven thematic categories: Repentance for the past; Perception of the illegal act; Factors related to working conditions; Psychological and/or social factors; Financial factors; Non-admission of liability; with responsibility and Duality between perception and fact.

Conclusion: The results of the study were extremely important to identify the occurrences involving criminal acts and demonstrate the need to broaden the discussion on ethical issues in daily nursing practice. In this perspective, the study demonstrates the need to invest in better working conditions and quality training for nursing professionals in their daily lives, valuing them and encouraging them to have an ethical and humane practice towards the other and themselves.

\section{Resumen}

Objetivo: Identificar tipos penales en el ejercicio de la enfermería y la existencia de factores relacionados con la conducta profesional en los casos éticos que incluyen tipos penales a partir del análisis de declaraciones en procesos éticos juzgados en el Consejo Regional de Enfermería de São Paulo (Coren/SP).

Métodos: Estudio exploratorio y descriptivo, de enfoque cuantitativo y cualitativo en procesos éticos que contienen ilícitos éticos considerados tipos penales. Los datos se recolectaron de los procesos ético-profesionales de enfermería juzgados por el Coren/SP en 2012 y 2013.

Resultados: Los tipos penales encontrados en el análisis fueron: abandono de incapaz; apropiación indebida; hostigamiento sexual; estafa; ejercicio ilegal de la profesión; ejercicio ilegal de la medicina; falsedad ideológica; pérdida, apropiación o inutilización de libro o documento; falsificación de documento; falsificación, corrupción, adulteración o modificación de producto destinado a fines terapéuticos o medicinales; hurto; homicidio; lesión corporal; malos tratos; malversación; tráfico de estupefacientes; uso de documento falso y profanación de cadáver. De las declaraciones surgieron siete categorías temáticas: Arrepentimiento posterior; Percepción del acto ilícito; Factores relacionados con las condiciones de trabajo; Factores psicológicos o sociales; Factores financieros; Incumplimiento de responsabilidad y Dualidad.

Conclusión: Los resultados del estudio fueron de suma importancia para identificar los casos que incluyen tipos penales y, por lo tanto, también lo es la necesidad de profundizar la discusión sobre problemas éticos en la práctica cotidiana del trabajo de enfermería. Bajo esta perspectiva, el estudio denota la necesidad de invertir en mejores condiciones de trabajo y en la formación calificada de los profesionales de enfermería en su cotidianidad, además de valorizarlos e incentivarlos a una práctica ética y humanizada del otro y de sí mismo.

\section{Introdução}

Ao analisar a prática profissional, deparamo-nos no âmbito nacional, com vários estudos relacionados a erros e danos causados pela realização de procedimentos, ${ }^{(1-3)}$ mas pouco acerca de danos ou riscos em decorrência da prática de ilícitos penais. Nessa esteira, urge necessária tal abordagem, bem como do conhecimento acerca de eventuais fatores que possam levar o profissional ao cometimento de um ato considerado lesivo a sociedade e a imagem da categoria.

Os profissionais devem ser conhecedores de suas competências e limitaçóes, com uma atuação vinculada aos ditames éticos e legais que norteiam a profissão, pois a ética nos conduz a convivência equilibrada e a lei ao reconhecer uma profissão, estabelece os limites de sua atuação. Porém, o profissional não somente está vinculado à legislação profissional, como sua atuação deve estar em consonância com as demais legislaçóes, ressaltando que o não cumprimento pode gerar responsabilizaçóes nos âmbitos cível, administrativo, ético-profissional e penal.

Estudo sobre erro médico cita matéria jornalística do ano de 2015 sobre a incidência de açóes judiciais por erro médico no Superior Tribunal de
Justiça-STJ, chamando a atenção para o acréscimo de $160 \%$ do número de açôes em relação aos anos anteriores. Ainda, no mesmo estudo, cita-se matéria de outra região do país que traz a informação de que no Brasil, nos 10 anos anteriores, houve um aumento de $1600 \%$ açóes judiciais por erro médico e que as condenaçóes de profissionais da medicina estavam em 180\% aumentadas em relação aos anos anteriores. ${ }^{(4)}$

Não podemos desconsiderar esses dados, uma vez que tanto na mídia como na doutrina em geral, por vezes relaciona-se erro médico a erros cometidos por profissionais de saúde. Equivocamente, relacionam-se as profissóes da saúde ao exercício da medicina, independente de possuírem legislaçóes próprias e autonomia profissional.

No âmbito penal, não podemos olvidar da possibilidade de majoraçáo da pena, conforme previsto no Código Penal Brasileiro (CPB), se o crime resulta de inobservância de regra técnica de profissão, como por exemplo, na ocorrência dos tipos penais de lesão corporal e homicídio. Ainda, as penas restritivas de direito têm impacto no âmbito profissional em relação a interdição temporária, que é a proibição do exercício de profissão que dependa de licença ou autorização do poder público, como no caso das 
profissóes regulamentadas, em todo crime cometido no exercício da profissão, sempre que houver violação dos deveres que lhes são inerentes. ${ }^{(5)}$

Porém, independente da responsabilização criminal, o profissional ainda está sujeito a responsabilização ética pelas ocorrências no exercício profissional relacionadas a tipos penais, sendo a análise realizada a partir do disposto no Código de Ética Profissional de Enfermagem (CEPE), atualmente reformulado pela Resolução COFEN 564/20173, ${ }^{(6)}$ cuja aplicação atinge todas as relaçôes que envolvem os profissionais inscritos nos Conselhos de Enfermagem.

Em relação aos crimes e contravençóes penais, o CEPE atual destaca em seu artigo 70, a proibição de "utilizar de conhecimentos da enfermagem para praticar atos tipificados como crime ou contravenção penal, tanto em ambientes onde exerça a profissão, quanto naqueles em que não a exerça", além de constar no artigo 72 a proibição da "prática ou conivência com crime, contravenção penal”.

Ante o exposto, este trabalho tem como objetivo analisar o conteúdo dos depoimentos dos profissionais de enfermagem responsabilizados eticamente por ocorrências éticas envolvendo tipos penais nos processos éticos julgados pelo Coren-SP.

\section{Métodos}

Trata-se de estudo exploratório-descritivo com abordagem quanti-qualitativa dos documentos existentes nos processos éticos (PE) julgados no Coren/ $S P$ relacionados a tipos penais. Foi realizada a coleta e análise de dados quantitativos, seguidas de coleta e análise de dados qualitativos. $\mathrm{O}$ recorte temporal foi estabelecido nos anos de 2012 e 2013, pois foi o período analisado na dissertação da pesquisadora, cujos dados motivaram o presente estudo.

Do corpus documental inicial de 254 processos envolvendo 399 profissionais julgados em 2012 e 2013, foram identificados 169 profissionais envolvidos em ilícitos éticos considerados tipos penais, tais como: abandono de incapaz; apropriação indébita; assédio sexual; importunação sexual; estelionato; estupro; exercício ilegal de profissão; exercício ilegal da me- dicina; falsidade ideológica; extravio, sonegação ou inutilização de livro ou documento; falsificação de documento; falsificação, corrupção, adulteração ou alteração de produto destinado a fins terapêuticos ou medicinais; furto; homicídio; injúria; lesão corporal; maus tratos; peculato; tráfico de entorpecentes; uso de documento falso e vilipêndio a cadáver.

O quantitativo de tipos penais foi identificado por meio de instrumento de coleta de dados, contendo dados gerais, dados dos profissionais e dados processuais, sendo neste último identificados os depoimentos em fase de averiguação (perante autoridades policiais ou judiciárias, Comissão de Ética de Enfermagem ou fiscalização) e após a instauração do processo ético (perante a comissão de instrução, na apresentação de defesa e alegações finais, e durante o julgamento), ressaltando o seguimento a Resolução COFEN 370/2010 que disciplina as fases do processo ético-disciplinar. ${ }^{(7)}$

Para a análise qualitativa foram selecionados 13 processos com desfecho condenatório para os profissionais, envolvendo 18 tipos penais distintos e que atenderam os seguintes critérios de inclusão: trânsito em julgado (trânsito em julgado: que não cabe mais recurso) da decisão, processo contendo ao menos um dos tipos penais identificados nos processos com culpabilidade e institucionalização da denúncia, considerando a existência de documentos que comprovassem instauração nas esferas criminal (inquérito ou processo criminal) ou administrativa. Foram excluídos da amostra os processos cujos profissionais foram absolvidos, não sendo contemplados, portanto, os processos relacionados aos seguintes tipos penais: estupro, injúria e assédio sexual.

No tratamento qualitativo dos dados, foi utilizada a análise de conteúdo visando obter, por procedimentos sistemáticos e objetivos, indicadores que permitiram a inferência de conhecimentos relativos às condições de produção/recepção das mensagens. ${ }^{(8)}$ O percurso analítico teve o sentido de tornar possível a objetivação de crenças, valores, representações, relaçôes e açôes humanas e sociais sob a perspectiva dos atores em intersubjetividade. ${ }^{(9)}$

Procedeu-se a leitura dos textos extraídos dos depoimentos "puros" dos profissionais, ou seja, os que partiram dos próprios profissionais e não de 
seus representantes, advogados ou defensores dativos. A dualidade dos discursos e a menção a fatores psicossociais e econômicos como justificativa, traziam importante carga valorativa, sendo o início do agrupamento de núcleos temáticos. Para apreender os núcleos de sentido, considerando a incidência do conteúdo semântico e similaridade, seguiram-se as etapas de pré-analise, exploração do material, tratamentos dos resultados e interpretação.

Os dados foram coletados nos arquivos do CorenSP após autorização formal, utilizando-se de instrumento de coleta, sendo o presente artigo parte da tese da autora. $\mathrm{O}$ projeto foi submetido à aprovação do Comitê de Ética e Pesquisa, conforme previsto na Resolução CNS no 466/2012, parecer no 3.389.575, em atendimento as normas nacionais e internacionais de ética em pesquisa envolvendo seres humanos.

\section{Resultados}

Os tipos penais elencados nos processos analisados com os artigos correspondentes, e as respectivas penalidades foram: P1- Abandono de incapaz e maus tratos (133 e $136 \mathrm{CPB})$ : censura e multa; P2 Apropriação indébita e estelionato (168 e 171 CPB): advertência e multa; P3 - Exercício ilegal e falsidade ideológica (47 da Lei das Contravenções penais e 299 CPB): Cassação do exercício por 03 anos; P4 - Extravio, sonegação ou inutilização de documento (314 CPB): censura e multa; P5 - Falsificação de documento público (297 CPB): multa; P6 Falsificação, corrupção ou adulteração de produtos destinados a fins terapêuticos (273 CPB): censura e multa; P7 - Furto (155 CPB): advertência verbal; P8 - Homicídio (121 CPB): Cassação do exercício por 05 anos; P9 - Lesão corporal (129 CPB): advertência verbal e multa; P10 - Maus tratos e importunação sexual (136 e 215-A CPB): censura e multa; P11 - Peculato e tráfico de entorpecentes (312 CPE e 33 Lei de drogas): censura e multa; P12 - Uso de documento falso e exercício ilegal da medicina (304 e 282 CPB): censura e multa e P13 - Vilipendio a cadáver (212 CPB): multa.

A partir dos depoimentos dos profissionais, emergiram 07 categorias temáticas, numeradas em ordem sequencial de P1 a P13 e com identificação dos profissionais utilizando as siglas: Enfermeiro (E), Técnico de Enfermagem (TE) e Auxiliar de Enfermagem (AE), conforme trechos a seguir:

\section{Categoria I: Arrependimento Posterior}

A categoria emergiu dos depoimentos que lamentaram o fato e relataram sofrimento pela falta praticada, bem como pela manifestação direta do profissional:

AE (P2) "Ateou fogo em todos os pertences por arrependimento e após a sentença devolveu o dinheiro".

AE (P5) "Pedir perdáo seria nada perante a burrada e a traição que eu fiz, eu não pensei nas consequências".

$A E$ (P11) "O que fiz foi errado e estou pagando muito caro por este ato, perdi meu emprego, de 20 e poucos anos como funcionário público, perdi o respeito dos meus colegas, perdi a dignidade”.

\section{Categoria II: Percepção do ato ilícito}

A categoria foi relacionada aos depoimentos que reconheceram o erro ou pela verbalização da culpa pelo ato praticado:

\section{AE (P2) "Não sabe explicar o motivo pelo qual cometeu o ato ilícito".}

AE (P5) "Afirma ter ciência de que auxiliares em saúde náo podem preencher atestados médicos assim como utilizarem carimbo de terceiros".

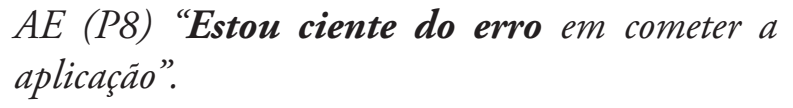
aplicação".

$A E$ (P11) "O referido processo onde sou enquadrado, venho salientar que sim, tenho a culpa do fato em questão".

\section{Categoria III: Fatores relacionados as condições de trabalho}

A categoria emergiu dos depoimentos que descreviam condiçóes de trabalho a que estavam expostos 
como dupla jornada, baixos salários, sobrecarga de trabalho e falta de treinamento:

TE (P1) "Havia muita rotatividade de funcionários, pelo salário baixo e muito serviço".

AE (P4) "Foi apenas por esquecimento devido à sobrecarga de trabalhar em dois hospitais".

AE (P9) "Antes dos fatos náo passou por treinamento formal sobre a punção e contenção de membros, nunca foi apresentada a manual de normas e rotinas, tampouco sabe da experiência deste documento em sua unidade".

AE (P9) "Relata que no momento dos fatos não se sentia cansada ou desconcentrada, embora o plantáo de 12 horas que havia realizado na pediatria tenha sido corrido".

\section{Categoria IV: Fatores psicológicos e/ou sociais}

A categoria emergiu dos depoimentos que manifestaram aspectos psicológicos ou sociais anteriores ou posteriores ao fato:

TE (P3) "As infundadas acusaçóes que foram lançadas sobre sua pessoa causaram uma pesada carga emocional, gerando distúrbios psicológicos representativos".

AE (P8) “O depoente já tentou suicídio por várias vezes em decorrência dos fatos".

AE (P9) "Foi muito difícil para sua vida pessoal a repercussáo dos fatos, principalmente porque seu filho de 7 anos não queria ir para a escola e a recriminava pelo ocorrido".

E (P12) "Que informou que após haver sido descoberto os fatos a interrogada tentou suicídio e encontra-se atualmente em tratamento psiquiátrico".

\section{Categoria V: Fatores financeiros}

A categoria foi relacionada aos depoimentos que manifestaram direta ou indiretamente a prática do ato ilícito por situaçóes ligadas a fatores financeiros:
AE (P6) "Fazia esse tipo de comércio para aumentar sua renda".

$A E$ (P7) "Que agiu por desespero em razão das dívidas contraídas".

$A E$ (P8) "Acha que errou ao executar um procedimento que náo era de sua competência e o fez por dinbeiro, para sustento próprio".

E (P12) "Tendo aceitado o emprego, pois estava desempregada e também passava por problemas pessoais, depressivos e financeiros".

$A E$ (P2) "Pegou o cartão de débito da CEF em nome do paciente, junto com a senha, e que fez várias compras no mesmo dia, argumentando nas lojas que o cartão era de seu avô".

AE (P5) "Afirma que os atestados foram feitos por ela a pedido de seu marido, pois ele encontrava-se em periodo de experiência na empresa e temia ser despedido".

\section{Categoria VI: Inobservância de responsabilidade}

A categoria VI foi relacionada somente aos depoimentos dos profissionais que manifestaram explicitamente a inobservância de responsabilidade ética ou legal, relacionadas a situaçóes de competência profissional, rotinas institucionais e ao respeito e dignidade do ser humano, uma vez que todos os processos analisados se relacionam à inobservância de responsabilidade ética, tendo em vista os desfechos de culpabilidade já apresentados:

$A E$ (P8) "Nâo se considera responsável pelo óbito, por ser o produto aplicado inerte e sempre aplicado junto ou posterior ao musculo".

E (P12) "Como não era médica, a declarante tirou uma fotocópia de seu diploma de enfermeira e adulterou o título da cópia do diploma mudando o titulo ENFERMEIRO para MÉDICO. Na ocasião a declarante já possuía uma cópia da carteira do CRM de sua irmá que é médica, inserindo na cópia deste documento seu nome". 
AE (P11) "Refere que subtraia as medicaçóes eventualmente, sempre aquelas ampolas que pertenciam a algum paciente que havia ido a óbito ou recebido alta hospitalar".

AE (P13) "A declarante informa que por curiosidade através de seu aparelho celular tirou algumas fotos do corpo da vítima enquanto a mesma estava na maca da sala de emergência".

\section{Categoria VII: Dualidade entre o percebido e o ocorrido}

A categoria VII emergiu dos depoimentos profissionais que manifestaram contradição em oposição as diretrizes éticas e/ou legais ou negaram os fatos atribuídos independente de todo conteúdo probatório apresentado:

AE (P6) "Outros medicamentos encontrados em sua maleta, afirma que compra no Paraguai para seu uso pessoal e as vezes fornece algumas destas medicaçôes aos seus colegas".

$A E$ (P8) "Sabia dos riscos, mas sempre soube que o PPMA oferecia riscos muito baixos. Após ler documento que a Anvisa emitiu sobre consulta acerca do PMMA, viu que tal uso é restrito a médico, fato que só soube depois do óbito".

AE (P10) "Quanto a denúncia de prática de atentado violento ao pudor o profissional nega".

TE (P3) "Não é a declarante a pessoa que praticou o crime".

AE (P6) "Nega venda de morfina e Panceron para qualquer pessoa e também nega que tenha deixado de medicar algum paciente que estivesse com dor para guardar a medicação.

\section{Discussão}

Os problemas éticos não estão relacionados somente a questôes procedimentais, ocorrendo nas mais diversas relaçôes, tendo em vista a essência do ser humano. ${ }^{(10)}$ Não podemos olvidar que ao abordarmos a ocorrência de tipos penais na assistência de enfermagem, nos deparamos com conflitos éticos que envolvem valores, normas e deveres profissionais, em uma profissão permeada pelo contato com o ser humano.

Em relação aos processos analisados, as penalidades aplicadas variaram de advertência a cassação do exercício profissional, podendo ocorrer mais de uma penalidade por processo. Em relação aos tipos penais elencados nos processos éticos, há convergência com alguns estudos realizados em processos éticos nos Estados do Ceará, São Paulo e Santa Catarina. ${ }^{(11-13)}$

Quanto à análise por categorias, o artigo 16 do $\mathrm{CPB}$ enfatiza que o "arrependimento posterior" nos crimes cometidos sem violência ou grave ameaça à pessoa, poderá ocorrer a redução da pena, se reparado o dano ou restituída a coisa, por ato voluntário do agente até o recebimento da denúncia. ${ }^{(5)}$

Infere-se que, não obstante o descumprimento de um dever profissional e da normatização ética e legal que gerou a responsabilização dos profissionais no âmbito ético, o arrependimento manifestado nos depoimentos dos processos demonstra uma falibilidade humana diante de uma situação fática especifica, sendo possível diante do entendimento do profissional que sua conduta não foi a adequada, de maior possibilidade de aprendizagem em toda condução do processo.

No que diz respeito a categoria "percepção do ato ilícito", evidencia-se o reconhecimento do erro profissional, o que demonstra a importância de estimularmos a reflexão sobre o ilícito cometido e a consequente necessidade de aquisição de conhecimento para uma melhor tomada de decisáo, visando que o profissional tenha uma melhor percepção acerca da sua conduta, seus deveres e eventuais consequências de seu descumprimento.

No que tange às categorias "Fatores relacionados as condiçóes de trabalho"; "psicológicos e/ou sociais" e "financeiros", verificam-se depoimentos que carregam uma forte relação com fatores extrínsecos que podem potencializar as escolhas dos profissionais diante dos problemas éticos de forma consciente ou inconsciente. 
Os problemas associados com o número insuficiente de profissionais de enfermagem nas instituiçóes de saúde estão intimamente ligados à sobrecarga de trabalho destes, com o aumento da jornada de trabalho, aumento da rotatividade e às dificuldades de capacitação das equipes. ${ }^{(14)}$

Estudo destaca que de acordo com a literatura muitos são os problemas que emergem do exercício da enfermagem, como estarem inseridos em condiçóes de trabalho preocupantes e sobrecarregados devido a recursos humanos insuficientes. ${ }^{(15)}$

Estudo realizado pela Fiocruz afirma que os rendimentos obtidos pelos profissionais de enfermagem no exercício de atividade nos quatro grandes setores de empregabilidade configuram situação de subemprego, com existência de subsalário tanto no serviço público, como privado e filantrópico. ${ }^{(16)}$

Outro estudo, que trata da ansiedade, depressão e suporte social em profissionais de enfermagem, destaca que os profissionais enfermeiros estão entre os profissionais mais susceptíveis aos problemas de saúde mental diante da maior permanência com indivíduos que necessitam de ajuda, e das pressóes constantes no trabalho que contribuem sobremaneira para danificar sua saúde mental. ${ }^{(17)}$

Quanto à categoria "Inobservância de responsabilidade", percebe-se a inobservância dos ditames éticos e legais de forma consciente a partir dos depoimentos trazidos. Porém, o profissional só será ético quando atuar conforme os princípios propostos em seu código de ética, a partir de sua interpretação e compreensão, sendo o conceito de responsabilidade ética a obrigação de responder pelo ato praticado e suas consequências. ${ }^{(18)}$

Em relação ao aspecto deontológico da categoria, artigo destaca que o conhecimento limitado dos trabalhadores de enfermagem sobre o Código de Ética Profissional pode promover um distanciamento entre o trabalho efetivamente realizado e suas competências éticas e legais. ${ }^{(19)}$

Concernente à categoria "Dualidade entre o percebido e o ocorrido" percebe-se depoimentos defensivos, sem qualquer atribuição de sua conduta ao ato ilícito apresentado. Os depoimentos trazidos nessa categoria demonstram manifestaçóes sem empatia, independente do extenso conteúdo proba- tório existente nos processos que levou a condenação dos profissionais envolvidos, após o trânsito em julgado e respeitados os princípios de ampla defesa e contraditório.

Portanto, nessa categoria em específico, diante da contradição nos depoimentos e negação da conduta, traços de caráter são mais evidenciados, ressaltando-se que são de difícil mudança, diferentemente da possibilidade de conhecer competências e aprender habilidades. Os profissionais de saúde precisam desenvolver hábitos, habilidades e competências deliberativas para aumentar a qualidade da atenção à saúde. ${ }^{(20)}$

Os depoimentos revelam a importância do resgate ao processo de humanização não somente na prática assistencial, mas em relação aos profissionais que atuam nos diversos níveis de atenção à saúde, ao longo da formação permanente do profissional.

Para a tomada de decisão, necessário o conhecimento dos valores que motivaram e justificaram as açôes. Para se analisar o processo e o desfecho, é preciso deliberar sobre os fatos, sobre os valores em conflito, sobre os deveres e responsabilidades. ${ }^{(21)}$

\section{Conclusão}

Os resultados do estudo foram de suma importância para identificar as ocorrências envolvendo tipos penais e ampliar a discussão sobre os problemas éticos na prática cotidiana do trabalho em enfermagem, possibilitando a tomada de decisão mais prudente. A atuação profissional da equipe de enfermagem pauta-se para além da dimensão técnico-científica do conhecimento e do saber-fazer, a dimensão ética, que envolve o valor intrínseco das relações (profissionais e clientela assistida), respeitando-se a dignidade do próprio profissional e, sobretudo, do sujeito a quem este último deve dirigir sua atenção e cuidado. Nessa perspectiva, o estudo denota a necessidade de se investir em melhores condiçóes de trabalho e na formação qualificada dos profissionais de enfermagem no seu cotidiano, valorizando-os e incentivando-os à prática ética e humanizada do outro e de si. 


\section{Colaborações}

Mattozinho FCB contribui com a concepção do projeto, análise e interpretação dos dados e redação do artigo. Freitas GF contribuiu com a revisão crítica do conteúdo intelectual e aprovação final da versão a ser publicada.

\section{Referências}

1. Coimbra JÁ, Cassiani SH. Responsabilidade da Enfermagem na administração de medicamentos: algumas reflexões para uma prática segura com qualidade de assistência. Rev Lat Am Enfermagem. 2001;9(2):56-60.

2. Coli RC, Anjos MF, Pereira LL. Postura dos enfermeiros de uma unidade de terapia intensiva frente ao erro: uma abordagem à luz dos referenciais bioéticos. Rev Lat Am Enfermagem. 2010;18(3):27-33.

3. Carboni RM, Reppetto MA, Nogueira VO. Erros no exercício da enfermagem que caracterizam imperícia, imprudência e negligência: uma revisão bibliográfica. Rev Paul Enferm. 2018;29(1/3):100-7.

4. Gomes TR, Pires de Sá MC. 0 Erro médico sob o olhar do Judiciário: uma investigação no Tribunal de Justiça do Distrito Federal e Territórios. Cad Ibero Am Dir Sanit (Brasília). 2017; 6(1):72-85.

5. Brasil. Leis, Decretos. Lei n. 2.848, de 07 de dezembro de 1940. Dispõe sobre a criação do Código Penal. Diário Oficial da União, Brasília, 07 dez. 1940. Disponível em: http://www2.camara.leg.br/ legin/fed/declei/1940-1949/decreto-lei-2848-7-dezembro-1940412868-publicacaooriginal-1-pe.html

6. Conselho Federal de Enfermagem (COFEN). Resolução COFEN 564/2017 de 06 de dezembro de 2017. Aprova o Novo Código de Ética dos Profissionais de Enfermagem. Brasília (DF): COFEN; 2017.

7. Conselho Federal de Enfermagem (COFEN). Resolução COFEN 370/2010 de 03 de novembro de 2010. Altera o Código de Processo Ético das Autarquias Profissionais de Enfermagem para aperfeiçoar as regras e procedimentos sobre o processo ético-profissional. Diário Oficial da União. Brasília (DF); 2010. Disponível em: http://novo. portalcofen.gov.br/resoluo-cofen-n-3702010_6016.html
8. Minayo MCS. Analise qualitativa: teoria, passos e fidedignidade. Cienc Saude Coletiva. 2012;17(3):621.

10. Zoboli EL, Fortes PA. Bioética e atenção básica: um perfil dos problemas éticos vividos por enfermeiros e médicos do Programa Saúde da Família, São Paulo, Brasil. Cad Saude Publica. 2004;20(6):1690-9.

11. Mendonça FA, De Menezes MV, Amorim SC, De Morais FD, Feitosa EM, Lacerda CM. Processo ético de enfermagem no Estado do Ceará: reflexão para prática profissional. Enferm Foco. 2017;8(2):77-81.

12. Mattozinho FC, Freitas GF. Ocorrência éticas no Estado de São Paulo: descrição fática. Acta Paul Enferm. 2015;28(6):593-600.

13. Schneider DG, Ramos FR. Processos Éticos de enfermagem no Estado de Santa Catarina: caracterização de elementos fáticos. Rev Lat Am Enfermagem. 2012;20(4):744-52.

14. Forte EC, Pires DE, Martins MM, Padilha MI, Ghizoni Schneider D, Trindade LL. Processo de trabalho: fundamentação para compreender os erros de enfermagem. Rev Esc Enferm USP. 2019;53:e03489.

15. Silveira LR, Ramos FR, Schneider DG, Razquin MIS, Brehmer LC. Processo de deliberação moral dos enfermeiros de competência gerencial e fiscalizatória dos conselhos de enfermagem. Enferm foco. 2019; 10(3): 22-7.

16. Machado MH, Aguiar Filho W, Lacerda WF, Oliveira E, Lemos W, Wermelinger W, et al. Características gerais da enfermagem: o perfil sóciodemográfico. Enferm Foc0. 2016; 6(1/4): 11-7.

17. Gomes RK, Oliveira VB. Depressão, ansiedade e suporte social em profissionais de enfermagem. Bol Psicol (São Paulo). 2012;63(138):23-33.

18. Cortez EA, Sarte AP, Bento AA, Carmo TG, Nascimento RM. Responsabilidade ética e legal do enfermeiro na administração medicamentosa: 0 estado da arte. Rev Pesqui (Univ. Fed. Estado Rio J., Online). 2010; 2(3):1143-53.

19. Silva TN, Freire ME, Vasconcelos MF, Silva Junior SV, Silva WJ, Araújo PD, et al. Deontological aspects of the nursing profession: understanding the code of ethics. Rev Bras Enferm. 2018;71(1):3-10.

20. Zoboli EL. Bioética clínica na diversidade: a contribuição da proposta deliberativa de Diego Gracia. Rev Bioethikos (Centro Univ São Camilo). 2012;6910:49-57.

21. Zoboli EL. Tomada de decisão em bioética clínica: casuística e deliberação moral. Rev Bioét. 2013;21(3):389-96. 